\title{
SERUM PSA AND CURE PERSPECTIVE FOR PROSTATE CANCER IN MALES WITH NONPALPABLE TUMOR
}

\author{
MARCOS F. DALL'OGLIO, ALEXANDRE CRIPPA, CARLO C. PASSEROTTI, LUCIANO J. \\ NESRALLAH, KATIA R. LEITE, MIGUEL SROUGI \\ Division of Urology, Paulista School of Medicine, Federal University of Sao Paulo, UNIFESP, Sao Paulo, \\ SP, Brazil
}

\begin{abstract}
Introduction: Many studies have shown the association between PSA levels and the subsequent detection of prostate cancer. In the present trial, we have studied the relationship between preoperative PSA levels and clinical outcome following radical prostatectomy in men with clinical stage T1c.

Materials and Methods: 257 individuals with clinical stage T1c undergoing retropubic radical prostatectomy were selected in the period from 1991 to 2000. Following surgery, biochemical recurrence-free survival curves were constructed according to PSA levels between 0-4; 4.1-10; 10.120 and $>20 \mathrm{ng} / \mathrm{mL}$.

Results: Of the total of 257 selected patients, $206(80 \%)$ had Gleason scores from 2 to 6 and $51(20 \%)$, presented Gleason scores 7 and 8 , as defined by the pathological report from prostate biopsy. There was no biochemical recurrence of disease when the PSA was lower than 4, regardless of Gleason score. Biochemical recurrence-free survival according to PSA between $0-4 ; 4.1-10 ; 10.1-20$ and $>20$ was $100 \%, 87.6 \%, 79 \%$ and $68.8 \%$ for Gleason scores $2-6$ and $100 \% ; 79.4 \%$; $40 \%$ and $100 \%$ for Gleason scores 7-8 respectively. When all individuals were grouped, regardless of their Gleason scores, the probability of biochemical recurrence-free survival was $100 \%, 65.1 \%, 53.4 \%$ and $72.2 \%$ according to PSA between $0-4 ; 4.1-10 ; 10.1-20$ and $>20 \mathrm{ng} / \mathrm{mL}$ respectively.

Conclusion: Non-palpable prostate cancer presents higher chances of cure when the PSA is inferior to $4 \mathrm{ng} / \mathrm{mL}$.
\end{abstract}

Key words: prostate-specific antigen; prostatic neoplasms; prostatectomy; treatment outcome Int Braz J Urol. 2005; 31: 437-44

\section{INTRODUCTION}

Approximately $75 \%$ of men over 50 years old are screened for prostate cancer (PCa) by testing the prostate-specific antigen (PSA) (1); among those with altered PSA, two thirds will be identified as having $\mathrm{PCa}$ in stage T1c (2).

The indication for prostate biopsy when the PSA exceeds $4 \mathrm{ng} / \mathrm{mL}$ should be assessed on an indi- vidual basis, especially after recent data that showed PCa in 23.9 to $26.9 \%$ of men with PSA between 2 and $4 \mathrm{ng} / \mathrm{mL}$ (3).

One concern about the indiscriminate use of PSA is the diagnosis of insignificant tumors (4) and the treatment of eventual tumors with low biological aggressiveness. However, despite the initial identification of PCa, 25 to $33 \%$ of individuals will die as a consequence of the disease, though the majority is 
identified as T1c (2). The detection of early PCa increases the chances of disease confined to the prostate with lower risks of cancer recurrence following the treatment (5), while some authors already believe that the disease-related mortality is decreasing (6).

Due to the increasing debate concerning the upper normal limits for PSA (7), this study aims to assess preoperative PSA levels in individuals with $\mathrm{PCa}$ clinical stage T1c undergoing radical prostatectomy, as well as their postoperative outcome.

\section{MATERIALS AND METHODS}

The study assessed 257 men presenting a clinical diagnosis of PCa stage T1c, with a mean age of $63.2 \pm 7.5$ years $(47-76)$. The mean preoperative serum PSA was $8.7 \pm 5.6 \mathrm{ng} / \mathrm{mL}(0.3-32.0)$, and the mean postoperative follow-up time was $85.4 \pm 6.1$ months. These were retrospectively assessed.

The initial PSA was collected before prostate biopsy. During staging, all patients underwent anamnesis and physical examinations, alkaline phosphatase dosing, total and prostatic acid phosphatase, pelvic computerized tomography and bone scintigraphy in order to rule out extraprostatic disease.

All participants underwent retropubic radical prostatectomies with bilateral pelvic iliac lymphadenectomy at our institution from March 1991 to November 2000. The same surgeon (MS) performed all surgical procedures and the same pathologist (KRL) performed all pathological analyses.

Clinical staging was defined according to the American Joint Committee on Cancer classification (8), and histological grade according to Gleason score (9).

For selection of this group, cases receiving neoadjuvant or adjuvant hormone therapy (14 patients), as well as adjuvant radiotherapy (one patient), were excluded.

Postoperatively, patients were assessed every 2 months during the first year, then every 6 months for 5 years, and yearly from them on. During each assessment, patients underwent digital rectal examinations of the prostate cavity and analysis of serum PSA. Imaging exams (chest radiography, bone scintigraphy, abdominal tomography) were repeated ev- ery year. Biochemical progression was defined as a serum PSA higher than or equal to $0.4 \mathrm{ng} / \mathrm{mL}$, a cutoff value that was used by other authors as well (10).

The preoperative PSA was divided into categories of from 0 to $4 \mathrm{ng} / \mathrm{mL}, 4.1$ to $10 \mathrm{ng} / \mathrm{mL}, 10.1$ to $20 \mathrm{ng} / \mathrm{mL}$ and higher than $20 \mathrm{ng} / \mathrm{mL}$. (The distribution of patients according to preoperative PSA is in Table-1). Initially, we divided the patients into 2 groups: low risk (Gleason scores 2-6) and high risk (Gleason scores 7-10). Subsequently, we grouped all individuals together to build the survival curve.

For the statistical analysis, we used an approach of survival analysis considering the biochemical recurrence of the disease as the event of interest, defined by a PSA value higher than or equal to 0.4 $\mathrm{ng} / \mathrm{mL}$. For the disease-free survival curves, we used the Kaplan-Meier method and the Breslow and LogRank tests. A Cox regression model with proportional risks was adjusted on the multivariate analysis. P values $<0.05$ were considered to be statistically significant.

\section{RESULTS}

Table-1 presents the distribution of 257 patients with clinical stage T1c showing the incidence in relation to PSA values, where we can observe that $60 \%$ of them had PSA between 4.1 and 10.0.

Table-2 presents the 206 patients with clinical stage T1c and Gleason scores of 2-6 (low risk) in relation to PSA levels and events in relation to the assessed PSA categories. In Figure-1, we can see that PSA levels influenced the disease-free survival rates of patients with clinical stage T1c $(\mathrm{p}=0.008)$. We can also observe that none of the patients with PSA

Table 1 - PSA distribution in patients with clinical stage Tlc.

\begin{tabular}{lc}
\hline PSA & $\mathbf{N}(\%)$ \\
\hline $0-4.0$ & $17(6.7)$ \\
$4.1-10.0$ & $155(60.3)$ \\
$10.1-20.0$ & $67(26)$ \\
$>20.0$ & $18(7)$ \\
Total & $257(100.0)$ \\
\hline
\end{tabular}


Table 2 - Distribution of patients with clinical stage T1c and Gleason scores 2-6, according to PSA levels.

\begin{tabular}{lccc}
\hline PSA Levels & N Patients & N Events & \% Censorships \\
\hline $0-4.0$ & 12 & - & $100.0 \%$ \\
$4.1-10.0$ & 121 & 15 & $87.6 \%$ \\
$10.1-20.0$ & 57 & 12 & $79.0 \%$ \\
$>20.0$ & 16 & 5 & $68.8 \%$ \\
\hline
\end{tabular}

between 0 and 4.0 presented a recurrence of disease during the assessment period. When PSA levels oscillated between 4.1 and $20 \mathrm{ng} / \mathrm{mL}$, they showed the same prognosis $(\mathrm{p}=0.102)$ in relation to the expectancy of biochemical recurrence-free survival.
Table-3 represents the distribution of 51 patients with clinical stage T1c and Gleason scores of 7 and 8 according to PSA levels. It is important to stress that there was no patient with a Gleason score of 9 or 10 . The survival probability curve for bio-

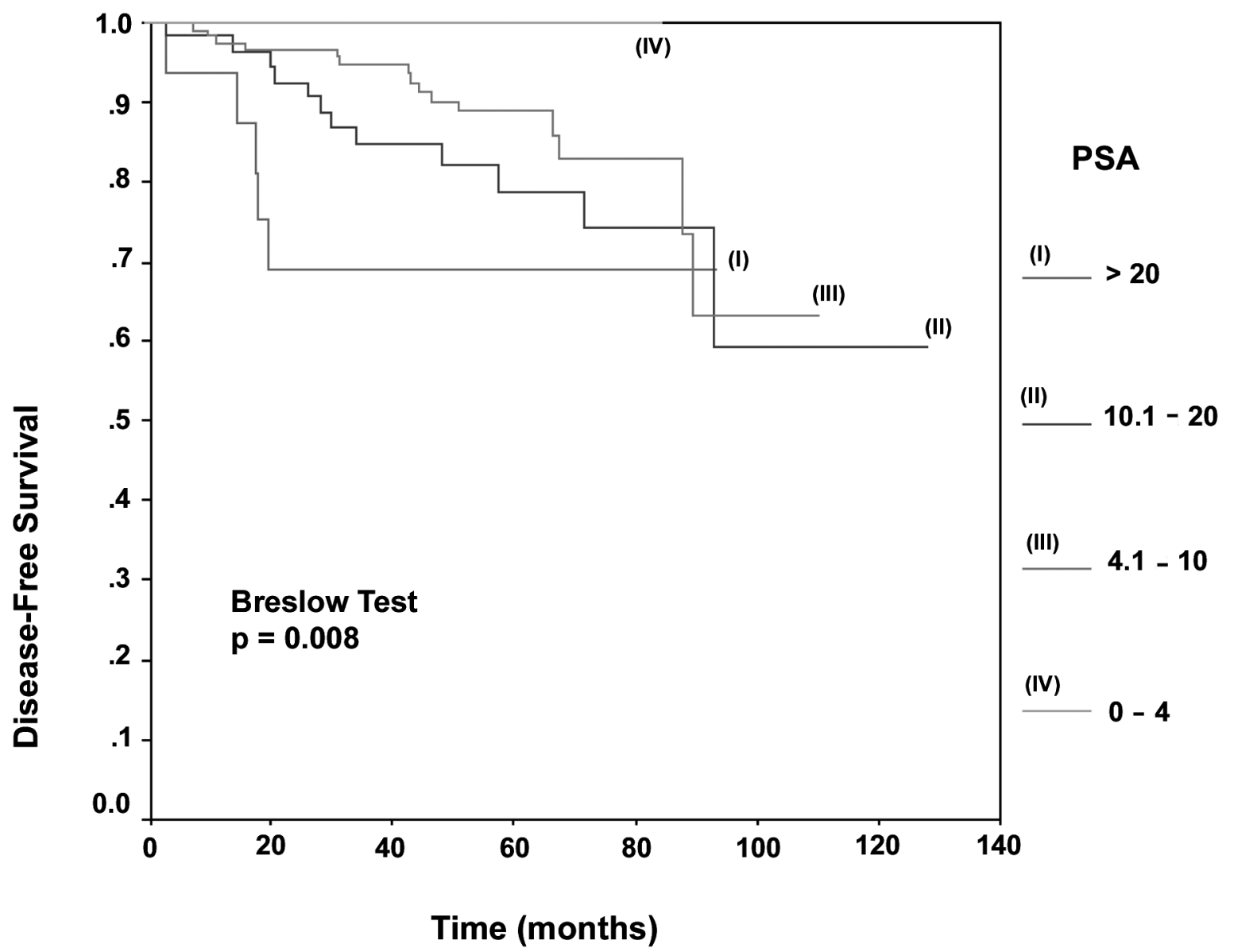

Figure 1 - Probability curve for recurrence-free survival according to PSA categories in patients with clinical stage T1c, and Gleason scores $2-6$. 
Table 3 - Distribution of patients with clinical stage T1c and Gleason scores 7 - 8, according to PSA levels.

\begin{tabular}{lccc}
\hline PSA Levels & N Patients & N Events & \% Censorship \\
\hline $0-4.0$ & 5 & 0 & $100.0 \%$ \\
$4.1-10.0$ & 34 & 7 & $79.4 \%$ \\
$10.1-20.0$ & 10 & 6 & $40.0 \%$ \\
$>20.0$ & 2 & 0 & $100.0 \%$ \\
\hline
\end{tabular}

chemical recurrence of disease according to PSA categories for patients with clinical stage T1c, Gleason scores 7 and 8 (Figure-2) show statistical significance ( $\mathrm{p}=0.039)$, when comparing PSA levels $<4 \mathrm{ng} / \mathrm{mL}, 4.1-10 \mathrm{ng} / \mathrm{mL}$ and $10.1-20 \mathrm{ng} / \mathrm{mL}$. Only 2 patients had Gleason 7-8 and PSA > $20 \mathrm{ng} /$ $\mathrm{mL}$; however, they did not present recurrence of dis- ease. These particular individuals had a follow-up of 19.5 months. Moreover, both specific individuals had PSA values of $21 \mathrm{ng} / \mathrm{mL}$ and $23.5 \mathrm{ng} / \mathrm{mL}$.

Finally, we constructed a graph (Figure-3) which groups all individuals, regardless of Gleason score, which is summarized in Table-4. In addition to the absence of biochemical recurrence with PSA $<4$

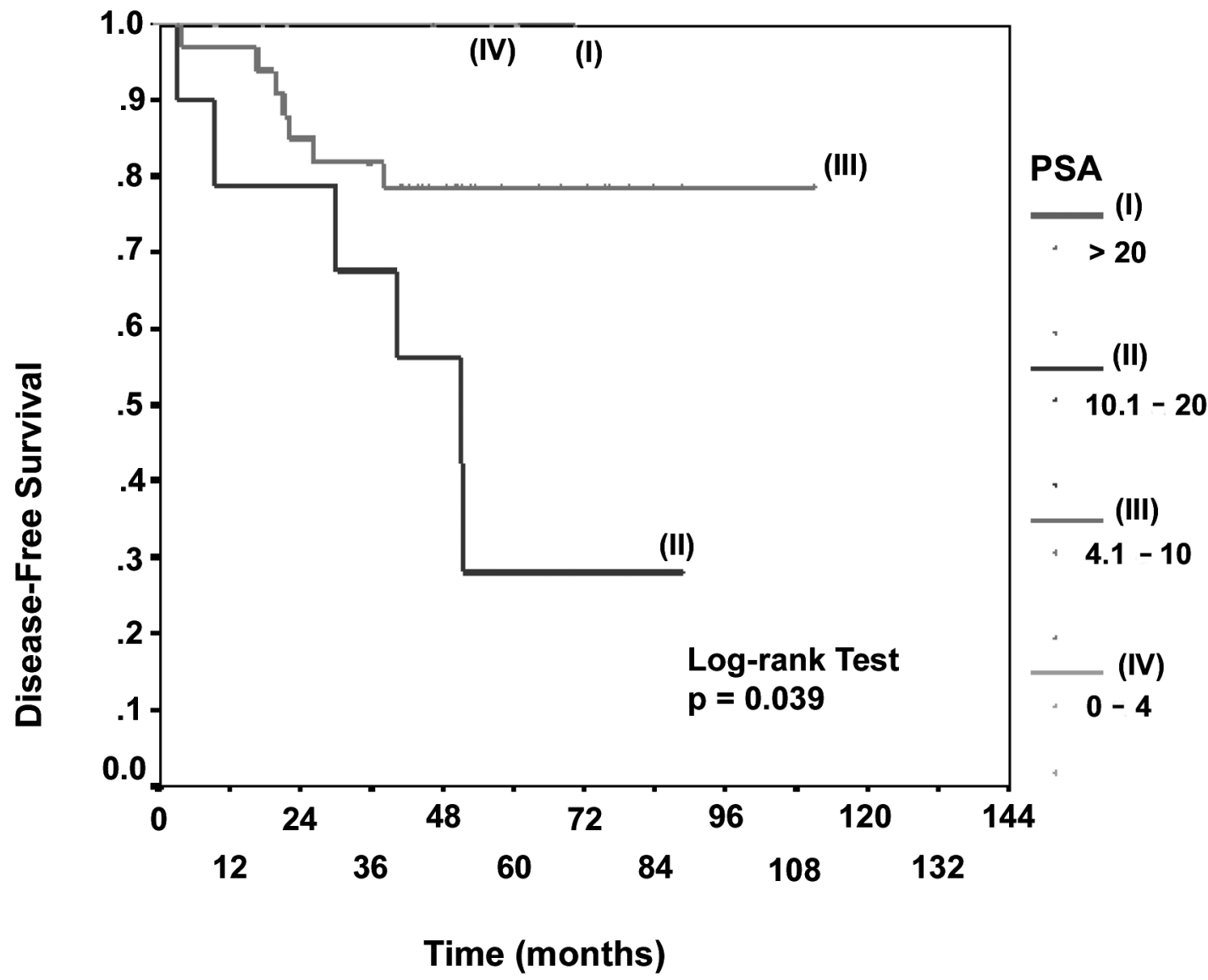

Figure 2 - Probability curve for recurrence-free survival according to PSA categories in patients with clinical stage T1c, and Gleason scores $7-8$. 


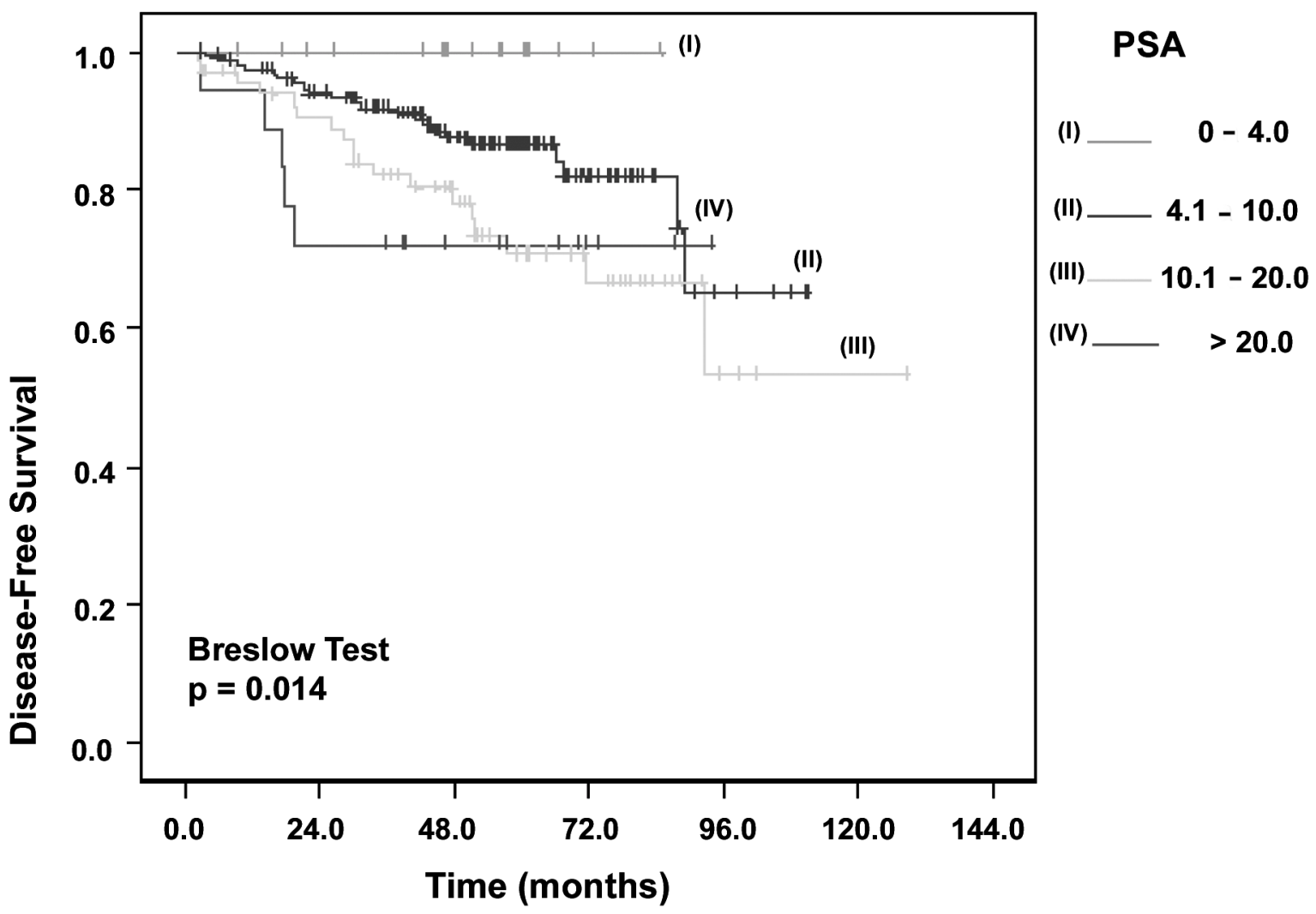

Figure 3 - Probability curve for recurrence-free survival according to PSA categories in patients with clinical stage T1c, and Gleason scores $2-8$.

$\mathrm{ng} / \mathrm{mL}$, even after a median follow-up of 85.4 months, it is important to stress that, for individuals with PSA 4.1 to $10.0 \mathrm{ng} / \mathrm{mL}$ after 89.1 months, the probability of remaining free of biochemical recurrence is $65.1 \%$. For patients with PSA of 10.1 to $20.0 \mathrm{ng} / \mathrm{mL}$, after 92.6 months the probability of being free of biochemical recurrence is $53.4 \%$. Finally, in men with PSA $>20.0 \mathrm{ng} / \mathrm{mL}$, the probability of being free of biochemical recurrence is $72.2 \%$; however, in this particular group, we stress that the median follow-up was substantially shorter - only 19.5 months.

\section{COMMENTS}

The study demonstrated that the life expectancy free of biochemical recurrence in individuals with $\mathrm{PCa}$ clinical stage $\mathrm{T} 1 \mathrm{c}$ and undergoing radical prostatectomy is higher in those with PSA inferior to 4 .

Table 4 - Distribution of patients with clinical stage T1c and Gleason scores 2 - 8, according to PSA levels.

\begin{tabular}{lccc}
\hline PSA Levels & N Patients & N Events & \% Censorship \\
\hline $0-4.0$ & 17 & - & $100.0 \%$ \\
$4.1-10.0$ & 155 & 22 & $85.8 \%$ \\
$10.1-20.0$ & 67 & 18 & $73.1 \%$ \\
$>20.0$ & 18 & 5 & $72.2 \%$ \\
\hline
\end{tabular}


From 1986 and 1999, the use of PSA for screening has reduced the incidence of metastatic $\mathrm{PCa}$ from 50 to $70 \%$ (11). Considered more lethal than cardiac disease for between 60 and 80 year olds, the $\mathrm{PCa}$ is currently diagnosed in its localized form in $86 \%$ of men (12). Additionally, pathological changes of the prostate are identified during autopsies in $64 \%$ of men aged between 60 and 70 years of age (13).

The assessment of PSA for screening PCa has enabled an early diagnosis and treatment of the disease. This statement can be corroborated by one study, which compared men with PCa clinical stage T1c and PSA between 2.6 and $4 \mathrm{ng} / \mathrm{mL}$, and individuals with PSA between 4.1-10 ng/mL (5). The study demonstrated that in the first group there are higher chances of organ-confined disease and lower tumor volume.

Johansson et al. (14) showed that observation could be dangerous to men with a life expectancy of over 10 years, demonstrating that after 15 years under a surveillance regimen the cancer-specific mortality increased from 15 to $44 / 1000$, progression-free survival dropped from $45 \%$ to $36 \%$, metastasis-free survival decreased from $76.9 \%$ to $51.2 \%$ and cancer-specific survival dropped from $78.7 \%$ to $54.4 \%$. These figures confirm that a long follow-up is required in PCa so that the benefits of early diagnosis and treatment can be observed. Additionally, the probability of death due to disease progression after 15-year surveillance increases from 4 to $30 \%$ with Gleason scores of 2-6 and 42 to $87 \%$ for Gleason scores of 7-10 (15).

In individuals under a surveillance regimen, the need for treatment was confirmed in $57 \%$ and $73.2 \%$ after 2 and 4 years respectively, with an increase in Gleason score in $24 \%$ of men after 3.8 years (16).

It is possible that non-palpable prostate tumors evidence significant disease, since this study has revealed a $12.4 \%$ chance of biochemical recurrence in individuals with PSA from 4.1 to $10 \mathrm{ng} / \mathrm{mL}$ and $21 \%$ when PSA are between 10.1 and $20 \mathrm{ng} / \mathrm{mL}$, in spite of stage T1c even in low risk tumors, with Gleason scores of 2-6. On the other hand, when we group all individuals regardless of Gleason score, the expectancy of biochemical recurrence-free survival remains at $100 \%$ when $\mathrm{PSA}<4 \mathrm{ng} / \mathrm{mL}$ and decreases drastically to $65.1 \%$ and $53.4 \%$ when the PSA is 4.1 - 10 and 10.1 - $20 \mathrm{ng} / \mathrm{mL}$ respectively.

When analyzing Figure-2, for PSA levels of $4.1-10 \mathrm{ng} / \mathrm{mL}$ and $10.1-20 \mathrm{ng} / \mathrm{mL}$, it is important to stress that the biochemical recurrence-free survival drops from $79.4 \%$ to $40 \%$ when only the Gleason score 7-8 is assessed, however it is $100 \%$ both in individuals with PSA lower than four and in the two patients with PSA higher than $20 \mathrm{ng} / \mathrm{mL}$. However, when all individuals are grouped (both low and high risk tumors as represented in Figure-3), the apparently contradictory probability of biochemical recurrence occurring in $72.2 \%$ of men with PSA > $20 \mathrm{ng} /$ $\mathrm{mL}$ is broken down - especially if we observe that in those particular cases the follow-up lasted only 19.5 months. Probably this percentage will decrease with evolving follow-up.

The need for surveillance in men between the fifth and the sixth decades of life should be considered. Some authors, by the way, advocate the performance of prostate biopsy establishing a PSA value up to $2.6 \mathrm{ng} / \mathrm{mL}$ as the upper normal limit (8) for men aged less than 60 years of age (11).

Since the classical concept by Whitmore (17) about the paradox existing in the treatment of $\mathrm{PCa}$ (is cure required when it is possible, or is it possible when it is required?), with the wide use of PSA in screening and the dramatic increase in the detection of organ-confined disease, the concept of clinically significant disease has become very important due to the risk of over treating the PCa. The main studies comparing radical prostatectomy with a surveillance regimen have been initiated in order to answer these questions. The Scandinavian prospective randomized study (6) assessing the development of metastasis in localized PCa has shown that metastases occurred in $13.4 \%$ and $27.3 \%$ for the surgery and the surveillance regimen groups respectively; in the untreated group the risk of metastases was $37 \%$ higher than in the group undergoing surgery with a median follow-up of 6 years. The risk of death after 8 years was $7.1 \%$ and $13.6 \%$ for the surgery and the surveillance regimen groups respectively; after a 10-year follow-up the risk of death increases to $16.8 \%$ in untreated men.

The concern to avoid over treatment in men with PCa should be carefully considered, however, 
the majority of T1c tumors are already significant tumors; that is, they present one of the following features on biopsy: Gleason patter 4, $=3$ positive fragments on biopsy and a fragment more than $50 \%$ affected by tumor (18). Carter et al. (19) obtained $31 \%$ of progression of disease during the first year of surveillance regimen in low risk tumors on the initial biopsy; that is, absence of primary Gleason pattern $4 / 5,<3$ positive fragments $/ 12$, no fragment more than $50 \%$ affected and PSA density of $<0.15$ ).

With the possibility of over treating the $\mathrm{PCa}$, currently $25 \%$ of men undergoing radical prostatectomy require a second therapy during the first 5 years following surgery (20). This figure begs the question of the correct PSA value that should be considered normal for each individual.

In order to illustrate the great dilemma concerning PCa screening, we need to evaluate the following situation: in Brazil, according to data from the Ministry of Health in 2005, there are approximately 23 million men between 40 and 79 years old. Among these men, and if we apply the worldwide statistics to our country, approximately $92 \%$ of men have PSA $<4 \mathrm{ng} / \mathrm{mL}$. Of those $8 \%$ of individuals with PSA $>4$, we will find $25 \%$ or 500,000 men with PCa. These figures are, to say the least, disturbing.

This study has some limitations, since it is retrospective and the digital rectal examination can be subjective. On the other hand, we considered as a positive factor the fact that it as a homogeneous group with follow-up longer than 7 years, which was assessed and operated on by the same surgeon.

We must make every effort to understand the natural history of prostate cancer, which is often unpredictable, and try to find the best moment for indicating prostate biopsy based on PSA.

\section{CONCLUSION}

With the acknowledgement of limitations in accuracy for identifying men with small volume cancer prostate, the attitude of avoiding biopsy can delay the diagnosis and result in losing the opportunity to cure.

Adriana Sañudo performed the statistical analysis

\section{REFERENCES}

1. Sirovich BE, Woloshin S, Schwartz LM: Screening men for prostate and colon cancer: are priorities in order? J Gen Intern Med. 2002; 17 (Suppl. 1): 212.

2. Cooperberg MR, Lubeck DP, Meng MV, Mehta SS, Carroll PR: The changing face of low-risk prostate cancer: trends in clinical presentation and primary management. J Clin Oncol. 2004; 22: 2141-9.

3. Thompson IM, Pauler DK, Goodman PJ, Tangen CM, Lucia MS, Parnes HL, et al.: Prevalence of prostate cancer among men with a prostate-specific antigen level < or $=4.0 \mathrm{ng}$ per milliliter. N Engl J Med. 2004; 350: 2239-46. Erratum in: N Engl J Med. 2004; 351: 1470.

4. Stamey TA, Freiha FS, McNeal JE, Redwine EA, Whittemore AS, Schmid HP: Localized prostate cancer. Relationship of tumor volume to clinical significance for treatment of prostate cancer. Cancer. 1993; 71 (Suppl 3): 933-8.

5. Krumholtz JS, Carvalhal GF, Ramos CG, Smith DS, Thorson P, Yan Y, et al.: Prostate-specific antigen cutoff of $2.6 \mathrm{ng} / \mathrm{mL}$ for prostate cancer screening is associated with favorable pathologic tumor features. Urology. 2002; 60: 469-73; discussion 473-4.

6. Stephenson RA: Prostate cancer trends in the era of prostate-specific antigen. An update of incidence, mortality, and clinical factors from the SEER database. Urol Clin North Am. 2002; 29: 173-81.

7. Hernandez J, Thompson IM: Prostate-specific antigen: a review of the validation of the most commonly used cancer biomarker. Cancer. 2004; 101: 894-904.

8. Beahrs OH, Henson DE, Hutter RVP: American Joint Committee on Cancer Manual for Staging Cancer. 4th Ed, Philadelphia, JB Lippincott. 1992.

9. Gleason DF: Histologic Grading and Staging of Prostatic Carcinoma. In: Tannenbaum M (ed.), Urologic Pathology. Philadelphia, Lea \& Febiger. 1977; pp. 171-87.

10. Ward JF, Blute ML, Slezak J, Bergstralh EJ, Zincke $\mathrm{H}$ : The long-term clinical impact of biochemical recurrence of prostate cancer 5 or more years after radical prostatectomy. J Urol. 2003; 170: 1872-6.

11. Carter HB: Prostate cancers in men with low PSA levels-must we find them? N Engl J Med. 2004; 350: 2292-4.

12. Jemal A, Tiwari RC, Murray T, Ghafoor A, Samuels A, Ward E, et al.: Cancer statistics, 2004. CA Cancer J Clin. 2004; 54: 8-29.

13. Sakr WA, Grignon DJ, Crissman JD, Heilbrun LK, Cassin BJ, Pontes JJ, et al.: High grade prostatic 
intraepithelial neoplasia (HGPIN) and prostatic adenocarcinoma between the ages of 20-69: an autopsy study of 249 cases. In Vivo. 1994; 8: 439-43.

14. Johansson JE, Andren O, Andersson SO, Dickman PW, Holmberg L, Magnuson A, et al.: Natural history of early, localized prostate cancer. JAMA. 2004; 291: 2713-9.

15. Albertsen PC, Hanley JA, Gleason DF, Barry MJ: Competing risk analysis of men aged 55 to 74 years at diagnosis managed conservatively for clinically localized prostate cancer. JAMA. 1998; 280: 975-80.

16. Carter CA, Donahue T, Sun L, Wu H, McLeod DG, Amling C, et al.: Temporarily deferred therapy (watchful waiting) for men younger than 70 years and with low-risk localized prostate cancer in the prostate-specific antigen era. J Clin Oncol. 2003; 21: 4001-8.
17. Whitmore WF Jr, Warner JA, Thompson IM Jr: Expectant management of localized prostatic cancer. Cancer. 1991; 67: 1091-6.

18. Epstein JI, Walsh PC, Carmichael M, Brendler CB: Pathologic and clinical findings to predict tumor extent of non-palpable (stage T1c) prostate cancer. JAMA. 1994; 271: 368-74.

19. Carter HB, Walsh PC, Landis P, Epstein JI: Expectant management of non-palpable prostate cancer with curative intent: preliminary results. J Urol. 2002; 167: 12314.

20. Lu-Yao GL, Potosky AL, Albertsen PC, Wasson JH, Barry MJ, Wennberg JE: Follow-up prostate cancer treatments after radical prostatectomy: a populationbased study. J Natl Cancer Inst. 1996; 88: 166-73.

Received: June 6, 2005 Accepted after revision: August 17, 2005

Correspondence address:

Dr. Marcos F. Dall'Oglio

Rua Barata Ribeiro, 398 / 501

São Paulo, SP, 01308-000, Brazil

Fax: + 5511 3159-3618

E-mail: marcosdallogliouro@terra.com.br 